\title{
O empresário na teoria econômica
}

\author{
The entrepreneur in the economic theory
}

\author{
JOÃO ANTÔNIO DE PAULA* \\ HUGO E. A. DA GAMA CERQUEIRA** \\ EDUARDO DA MOTTA E ALBUQUERQUE***
}

\begin{abstract}
RESUMO: Este artigo discute os papéis do empreendedor na teoria econômica. As deficiências da teoria mainstream são apontadas e as contribuições precursoras de Cantillon e Bentham são analisadas, bem como as diferentes abordagens de Marx, Veblen e Sombart. A mudança do papel do empreendedor após a emergência das corporações modernas é discutida, seguindo os trabalhos de Schumpeter, Penrose e Chandler.

PALAVRAS-CHAVE: Empreendedor; empreendedorismo; Schumpeter; cavaleiro; Marx.
\end{abstract}

ABSTRACT: This paper discusses the roles of the entrepreneur in the economic theory. The deficiencies of mainstream theory are pointed out and the forerunner contributions of Cantillon and Bentham are analyzed, as well as the different approaches of Marx, Veblen and Sombart. The changing role of the entrepreneur after the emergency of the modern corporations is discussed, following the works of Schumpeter, Penrose and Chandler. KEYWORDS: Entrepreneur; entrepreneurship; Schumpeter; knight; Marx. JEL Classification: B10; B20; M13.

\section{INTRODUÇÃO}

De Aristóteles a São Tomás de Aquino, pesou sobre a consciência ocidental um certo mal-estar no referente ao reconhecimento e legitimação da riqueza, do lucro, dos juros na medida em que estes são tidos como resultados de desigualdades das relações econômico-sociais. Mesmo a Reforma Protestante, que teria anistia-

* Centro de Desenvolvimento e Planejamento Regional da Universidade Federal de Minas Gerais CEDEPLAR-UFMG, Belo Horizonte/MG, Brasil, e-mail: jpaula@cedeplar.ufmg.br.

* Centro de Desenvolvimento e Planejamento Regional da Universidade Federal de Minas Gerais CEDEPLAR-UFMG, Belo Horizonte/MG, Brasil, e-mail: hugo@cedeplar.ufmg.br.

$* *$ Centro de Desenvolvimento e Planejamento Regional da Universidade Federal de Minas Gerais CEDEPLAR-UFMG, Belo Horizonte/MG, Brasil, e-mail: albuquer@cedeplar.ufmg.br. Submetido: Agosto 2002; aceito: Outubro 2003. 
do a busca do lucro, mesmo Calvino, tido como campeão da motivação protocapitalista, teriam lá suas reservas para com os ricos. Veja-se o trecho de Tawney:

"O calvinismo sentia pouca piedade para com a pobreza; mas desconfiava da riqueza, como desconfiava de todas as interferências que desviam da meta ou relaxam as fibras da alma e, no primeiro rubor da sua juvenil austeridade, esmerou-se em tornar insuportável a vida para o rico." (Tawney, 1971, p. 134)

Assim, está longe de ser linear e tranqüilo o itinerário da afirmação da legitimidade da função social do empresário na consciência comum da sociedade. É sinal disso, talvez, certa omissão ou secundarização do empresário em segmentos importantes do pensamento econômico. O processo de imposição do empresário como herói indispensável da epopéia capitalista, tomada como missão civilizatória, pode fornecer elementos significativos para a compreensão de aspectos importantes da relação entre pensamento econômico, cultura e realidade econômica capitalista.

Este texto é uma tentativa de apreender certas conexões de sentido entre pensamento e realidade econômica, a partir do suposto de que essas relações são marcadas pela complexidade e interdependência, para além de quaisquer reducionismos.

O primeiro a se destacar aqui é a existência de um, até certo ponto, surpreendente recato do pensamento econômico em apresentar o empresário como o herói de seu objeto de estudos. $\mathrm{Na}$ verdade, poucos foram os teóricos da economia que concederam lugar de destaque ao empresário em suas obras. Entre esses, destacamse Cantillon, Turgot e Schumpeter. Assim, esta operação ideológica, que tem buscado sancionar como positivo e indispensável o papel do empresário no mundo contemporâneo, tem que mobilizar variados instrumentos e veículos para a sua efetivação, tanto mais persuasivos quanto mais contundentes se apresentam certas suspeitas e denúncias de certa má-fé da atuação do empresário, como se vê tanto na literatura de um Balzac, por exemplo, quanto na sociologia econômica de um Veblen, que nos apresentam um certo tipo de empresário, sobretudo os do setor financeiro, mas não só estes, no limite do aceitável eticamente.

De tal modo que, encontrar-se elogio exaltado ao burguês, ao espírito empresarial, como o que fazem um Sombart ou Leroy-Beaulieu - "la fonction de l'entrepreneur d'industrie, de commerce ou de culture est, de toutes les fonctions de l'economie sociale, la plus elevée (...) Le entrepreneur est l'âme de la production $i$ il en a la responsabilité totale et définitive: tout le résultat lui en incombe en gain ou en perte matérielle, en honneur ou en honte" (Leroy-Beaulieu, 1914, p. 218) -, é parte de uma complexa disputa teórica, política e ideológica.

Quando surgiu, na França do século XVI, a palavra entrepreneur carregava um sentido que, até hoje, e problematicamente, se lhe é associado. Naquele tempo, entrepreneur designava os que dirigiam expedições militares e outras atividades tidas por aventureiras (Cochran, 1974). A partir de 1700, a palavra passa a ser usada para designar os empreiteiros de obras públicas e os arquitetos. Parece ter sido com Cantillon e Bernard Belidor, no século XVIII, que a palavra passará a desig- 
nar as atividades do empresário no sentido da compra e venda de trabalho e matérias-primas a preços não determinados a priori e a venda dos produtos resultantes a um preço contratado. Mas, é Cantillon quem vai identificar o decisivo atributo do empresário. É a aceitação e a lida com a incerteza, que vão, de fato, conceder funcionalidade e significado à ação do empresário (Cochran, 1974). Mais tarde, com Marshall e Schumpeter, vão ser reconhecidos dois outros sentidos justificadores da ação do empresário - este passará a ser caracterizado como aquele que corre riscos e é capaz de inovar.

Contudo, é da filosofia e da literatura que virão os temas e personagens que buscarão imprimir dignidade, e mesmo certo sopro épico, à figura do empresário. As figuras típicas deste processo de notabilização do empresário são Ulisses, o astuto e corajoso Odisseu; Prometeu, o herói civilizador, criador mítico da humanidade; e Fausto, o arquétipo do cientista benfazejo e dilacerado pela busca do absoluto e da compreensão integral da natureza.

Se estes são trópos fundantes, no Ocidente, do elogio do engenho, da ciência e da técnica, o itinerário destes personagens, suas recepções, por assim dizer, não estão isentas de contradições. A suspeita quanto ao caráter inequivocamente universal, emancipatório da ciência, da técnica, transformados em novas formas de poder, com algo de regressivo, deve-se à Escola de Frankfurt e foi ampliada com as denúncias provenientes da crítica ecológica.

Contudo, ainda que tenham certa audiência estas críticas e tenham mesmo atualidade contundente, domina o cenário ideológico contemporâneo a tese do irretorquível papel civilizador da ciência e da técnica e de seus titulares: o empresário e o cientista.

Oswald Spengler, em sua A decadência do Ocidente, vê a história das ciências da natureza como marcada pela evolução de três concepções: no mundo antigo, a alma apolínea, corresponderia à estática, a busca do equilíbrio, uma "física da proximidade", da matéria e da forma; no mundo medieval, a alma mágica, seria marcado pela alquimia, pela "representação de substâncias que têm efeitos misteriosos"; finalmente, no mundo moderno, a alma faústica, a física da força e da massa; é o mundo da dinâmica, uma "dinâmica do espaço ilimitado, uma física da distância” (Spengler, 1952, pp. 534-537).

Esta pretensão faústica, esta confiança e desassombro que reivindicam o movimento, a expansão sem fim, o ilimitado, é quase o programa justificador da ação empresarial no mundo moderno.

$\mathrm{Na}$ tradição do pensamento ocidental, Prometeu é a matriz da invenção, da técnica que permite a prosperidade material. Fausto, o cientista, é a matriz do movimento incessante da busca do conhecimento, as infinitas possibilidades da libertação da ciência de suas prisões teológico-metafísicas, diria Max Weber. Nesta mesma tradição, Ulisses é a matriz da astúcia, a justificação do sucesso pela vitória sobre a enormidade do mar, sobre seus perigos. Dizem Adorno e Horkheimer "o desamparo de Ulisses diante da fúria do mar já soa como legitimação do viajan- 
te que se enriquece à custa do nativo. Foi isso que a teoria econômica burguesa fixou posteriormente no conceito do risco: a possibilidade da ruína é a justificação moral do lucro" (Adorno e Horkheimer, 1988, p. 66).

É também como herói civilizador que Prometeu será apropriado pela modernidade a partir do romantismo, ele que fora herói mítico da antiguidade clássica.

Ésquilo escreveu uma trilogia que tem o titã, filho de Iápetos e Têmis, ou Climene, como herói criador e protetor da humanidade: Prometeu Acorrentado; Prometeu Liberto; Prometeu Portador do Fogo. O tema será retomado com o romantismo: em 1820, Shelley escreveu o Prometeu Desacorrentado, em que, contrariando o mito clássico, Prometeu não se submete à vontade de Zeus. Em 1884, Robert Bridges escreveu um poema chamado Prometheus, the Firegiver.

Prometeu, Fausto e Ulisses formariam, assim, uma tríade, freqüentemente usada, de símbolos autenticadores de certos valores, que se quer característicos do ethos empresarial burguês - a inventividade, a ousadia, a força... Em nossa época, David Landes escreveu O Prometeu desacorrentado, em que se lê - "ética faustiana, o senso de dominação da natureza e das coisas." (Landes, 1994, p. 30). Trata-se de uma reiteração significativa: a busca por parte da burguesia de uma mitologia capaz de justificar-qualificar sua ação, seus interesses. Esta dimensão progressiva, a obra revolucionária da burguesia, foi reconhecida por Marx e Engels no Manifesto comunista, numa análise que reproduz a tensionada trajetória de uma classe que liberta-revoluciona-abre caminho para o novo e neste mesmo movimento constrói as condições para a sua própria superação. Este destino trágico, faustiano, é o outro lado de uma imagem bifronte que também apresenta o brilho equilibrado de uma racionalidade colocada a serviço da invenção, do desenvolvimento material.

Contudo, não se veja este processo como linear, consensual ou unívoco. Tanto no plano das artes, da literatura, quanto no do pensamento econômico; na sociologia, a fixação do papel-significado do "empresário" não admite simplificações.

Veja-se Balzac. Este que talvez tenha sido o maior observador-historiador da consolidação da hegemonia burguesa no campo da literatura nos deu diversos tipos emblemáticos de empresários. O Barão de Nucingen é a encarnação do banqueiro; Gobsek, a personificação do agiota; César Birotteau, o perfumista, reproduz em sua trajetória "de grandeza e decadência" o destino comum de uma coletividade; Baltasar Cläès é a voragem da "busca do absoluto", a danação da pesquisa alquímica, a vertigem de uma inteligência, de uma racionalidade que desafia limites e precipita-se nos caos da alucinação, de uma razão ensandecida; David Séchard, um dos dois poetas das Ilusões perdidas, é o poeta da invenção, uma espécie de Fausto inteiramente voltado para a luz do progresso material e tecnológico. Sua pesquisa sobre a produção de papel, sua invenção de uma nova técnica de produção deste veículo das luzes, deste instrumento por excelência da disseminação do saber é o melhor e mais nobre da lição do Prometeu/Fausto. Mas, é no contraponto a David Séchard, nas figuras dos irmãos Cointet, que Balzac revelará 
a sua visão rigorosamente crítica e cética sobre o destino burguês. Os irmãos Cointet são a encarnação do capital triunfante, o capital que não inventa, que não tem compromisso com as luzes, que está longe de qualquer heroísmo, mas que acaba sendo o grande beneficiário e monopolista da invenção, do desenvolvimento científico e tecnológico. A vitória da mediocridade sobre o talento, da mesquinharia sobre o gênio, da venalidade sobre a ciência.

Os irmãos Cointet na crueza de suas ações, na eficácia de suas estratégias de controle, são a mais fiel reposição do papel efetivo do capitalista, seu destino e natureza - são personificações do capital, isto é, são movidos pelas motivações e interesses do capital; seus corações e cérebros de carne e sangue, têm a espessura e o desejo das máquinas e das coisas que buscam acumular incessantemente.

Também no plano do pensamento econômico, a figura do empresário foi representada de diferentes maneiras. Escapa inteiramente aos objetivos deste artigo fazer um levantamento exaustivo dos muitos papéis atribuídos a este personagem ao longo dos mais de dois séculos de ciência econômica. Vamos nos deter, ao contrário, na obra de uns poucos autores, escolhidos, sobretudo, pela natureza diferenciada de suas abordagens e pelas interpretações conflitantes que suscitaram. $\mathrm{O}$ texto está organizado em seis seções, além desta introdução. Na primeira, busca-se explicitar as relações entre a construção da figura do empresário, em suas diversas aparições, e a dinâmica histórica do capitalismo em suas contradições e exigências materiais e ideológicas. Trata-se, centralmente, de discutir o papel do empresário como sujeito decisivo do processo de competição capitalista. Partindo da constatação de que a teoria econômica convencional tem dificuldades para definir o papel do empresário, a seção seguinte discute as contribuições precursoras de Cantillon e Bentham, que antecipam as abordagens de Knight e Schumpeter. As duas seções posteriores enfocam a posição de Marx e as formulações de Veblen e Sombart, sugerindo a ascensão e queda da figura heróica do empresário. A sexta seção discute a requalificação do papel do empresário em função da emergência da grande empresa, tomando por base os trabalhos de Schumpeter, Penrose e Chandler. Finalmente, a última seção apresenta algumas notas conclusivas.

\section{EMPRESÁRIO E COMPETIÇÃO CAPITALISTA}

Como quase todas as realidades sociais, também a figura do empresário é uma construção histórica, isto é, sua imagem, sua recepção pela sociedade, sua valorização social dependem, ou antes, são resultados de uma complexa trama de circunstâncias em que estão presentes desde aspectos objetivos — a situação conjuntural da economia e suas repercussões sociais — até as interveniências derivadas da estrutura cultural, da dinâmica política, da hegemonia ideológica, da luta de classes. Neste sentido, diga-se, não há o empresário fixado, de uma vez por todas, por seus atributos funcionais, papel social ou pelas vicissitudes da sorte, senão que 
há, individual e coletivamente, uma imagem permanentemente retocada e cambiante, mudanças estas que denotam o lugar e a legitimação do lucro e seus detentores em cada contexto histórico concreto.

Durante o largo tempo da pré-modernidade, da tradição bíblica às prescrições antiusura do mundo medieval, foi com mal-estar que as sociedades encararam a riqueza que exorbita e seus titulares. São diferentes as motivações que levaram tanto o evangelho quanto a ética aristotélica a buscarem circunscrever a economia a preceitos éticos, isto é, subordinada ao império do bem comum e da integridade da comunidade. No entanto, em que pesem as diferenças, há um fundo comum nestas prescrições - a economia, a vida econômica, seus sujeitos e ações durante a prémodernidade não tinham autonomia, deviam se submeter aos ditames maiores da teologia ou de uma concepção metafísica do mundo, onde não há lugar para o indivíduo, para o interesse individual.

É com a modernidade, disse Max Weber, que tanto a ética, quanto a arte, quanto o conhecimento se autonomizam, isto é, "libertam-se" de seus constrangimentos teológicos e metafísicos. O resultado disto é o desencantamento do mundo, disse Weber, que tanto significará o extraordinário da revolução científica da modernidade, o avanço dos processos de racionalização em todas as esferas da vida social.

No que interessa mais imediatamente neste texto, trata-se de sublinhar a interação sistêmica das realidades do Estado, do indivíduo e do mercado. É o Estado moderno que possibilitará a emergência do indivíduo, na medida em que é o Estado que garantirá e proverá direitos individuais, o mesmo Estado que garantindo direitos individuais garantirá os contratos, sancionando a distribuição desigual dos recursos e da riqueza social.

É, então, também a modernidade, ao "autonomizar" a esfera ética, ao admitir a existência de éticas particulares, ao cancelar o mandato imperativo e universal dos preceitos éticos, processo que tem sua expressão clássica na ética protestante e na hipertrofia do individualismo que ela significa, que vai possibilitar que se suspenda a suspeita que até então pesava sobre o empresário, e que ele mesmo possa ser visto como herói.

É esta a situação que vai se por no século XVIII, simbolicamente encarnada em Robinson Crusoé, protótipo de toda a racionalidade individual com relação à economia. Se o empresário é reconhecido como herói civilizador no século XVIII, como se vê em Cantillon e Defoe, certas circunstâncias históricas, como a falência do banco de John Law, na França, em 1720, atualizou a velha desconfiança que não se afastará inteiramente no século XIX, onde Balzac será implacável na denúncia dos aspectos mais grotescos e venais da vida empresarial, que mesmo num país predisposto a aceitar a heroicidade do empresário, transformado em presentificação do peregrino-pioneiro, como os Estados Unidos, a lembrança dos "barões-ladrões" talvez cause certo mal-estar, que é reaquecido toda vez que um novo caso de corrupção empresarial é revelado. 
Trata-se de processo complexo, em que a ambigüidade é freqüente. Veja-se o referente à obra do Conde de Saint-Simon. Socialista utópico, como se sabe, SaintSimon viu na industrialização, no mundo industrial uma espécie de modelo para a organização socialista que ele imaginava, na medida em que a vida e o espaço fabril pareciam corresponder ao progresso e ao futuro que se buscava. Daí que SaintSimon tenha influenciado tanto a Comte, quanto aos irmãos Pereire, inovadores banqueiros franceses criadores do Crédit Mobilier; tanto ao crítico literário e escritor francês Saint-Beuve, quanto a Fedinand Lesseps, responsável pela abertura do Canal de Suez. É que o empresário que imaginou Saint-Simon é um herói que ainda não pode entrar no panteão da tradição romântica do século XIX. Carlyle, em seu livro clássico faz tipologia dos heróis: há os que são divindades; há os que são profetas, como Maomé; há os poetas, como Dante e Shakespeare, e há os sacerdotes, como Lutero; há os heróis das letras, como Rousseau e os heróis-reis como Cromwell e Napoleão, e os heróis revolucionários modernos (Carlyle, 1963). Mas não está lá o empresário. Mesmo o pensamento neoclássico na economia, em seu momento de máxima potência criativa, com Walras e os austríacos, não é capaz de fazer do empresário um herói sans phrase.

Foi Bujárin quem observou, com acerto, que no pensamento neoclássico walrasiano-austríaco a atividade do empresário-capitão-de-indústria, herói progressista - é deslocada do centro do mundo econômico, o qual teria seu sujeito decisivo no rentista (Bujárin, 1974).

É certo que uma das diferenças centrais entre o pensamento econômico clássico e o neoclássico reside na atribuição do lugar da produção nos dois universos teóricos, do que resulta a centralidade da produção no caso dos clássicos, e a virtual desaparição desta questão do universo walrasiano que se resume a operar as regras de equilíbrio numa economia de trocas. No entanto, mesmo em Smith ou Ricardo, o empresário não tem destaque conceitual - ele aparece como simples agente de uma imposição externa - as necessidades da acumulação de capital. É assim, também em Marx, nos dois primeiros livros de O capital, quando se considera apenas o capital em geral, quando são desconsideradas as singularidades do processo competitivo, que aparecem no livro III, de O capital. No entanto, é possível outra leitura do papel do empresário, de sua singularidade irredutível a qualquer esquematismo, considerá-lo como personagem decisivo, porque é um dos agentes principais do processo de competição capitalista, processo que é o da efetivação-materialização das categorias econômicas, da formação efetiva dos preços, da distribuição da renda.

Neste sentido, a reticência do pensamento econômico clássico e neoclássico em reconhecer o papel do empresário, que teve longa vigência, e é até hoje questão malentendida neste campo, decorre da incapacidade desta tradição teórica em entender o significado de uma teoria da concorrência capitalista.

Fragmentos de uma tal teoria encontram-se em alguns teóricos com sensibilidade para as questões históricas e institucionais como Sombart, Veblen, Schumpe- 
ter, Keynes. Contudo, é em Marx, nos seus aportes para uma teoria da concorrência que se encontram no livro III de O capital, é que se encontram os elementos conceituais decisivos para que estas contribuições possam ser articuladas coerentemente.

No centro desta perspectiva, que ainda não se realizou inteiramente, está o arcabouço geral de uma teoria de formas de extração da mais-valia extraordinária, do lucro extra, que, sendo o território da competição capitalista, é o mundo do empresário, de suas estratégias, de suas associações, de seus relacionamentos e consórcios com autoridades e competidores, de sua capacidade intransferível, de seu conhecimento e experiência.

Foi isso o que viu Sombart e que fixou em seu O burguês, de 1913, que antecipa muitas das teses de Schumpeter, de 1942, no Capitalismo, socialismo e democracia, no relativo aos perigos da destruição do espírito do capitalismo pelo avanço do rentismo e da burocratização (Sombart, 1953, p. 339).

Tanto Schumpeter, quanto Sombart, quanto antes deles, Cantillon, têm razão em atribuir importância ao empresário. É de sua atividade não-rotineira, isto é, é do aguilhão da concorrência que o sistema capitalista se move por meio de inovações. E aqui alargue-se o conceito schumpeteriano, que já é amplo como se sabe, para considerar em seu âmbito todas as estratégias que o empresário tem que mobilizar para superar seus concorrentes e, assim, se manter como capitalista.

É, talvez, para muitos paradoxal que se reivindique aqui a importância do papel do empresário, como sujeito que põe em marcha a concorrência, na teoria de Marx. Este possível espanto e estranhamento derivam, certamente, do amplo desconhecimento e incompreensão, freqüentes, sobre a obra de Marx, e, especificamente, da centralidade de uma teoria da concorrência no seu projeto inconcluso. Em mais de uma ocasião Marx explicitou a importância do tema e mesmo planejou dedicar um livro inteiro ao assunto. Como foi dito por Roman Rosdolsky,

"el mercado mundial, sus conyunturas, el movimiento de los precios corrientes, los períodos de crédito, los ciclos de la indústria y comércio, la prosperidad y la crisis alternativamente"... "Tales son los problemas que Marx reservó para una 'continuación eventual' y que solamente trató en El Capital de manera o en conexión com otros temas. A nuestro parecer, los problemas más importantes son los del mercado mundial, las crisis económicas y ‘el movimento real de los precios' (que Marx declaró expresamente que queria enlazar 'com uma investigación particular sobre la competencia').” (Rosdolsky, 1972, p. 234).

Neste sentido, registre-se a omissão e a precariedade de visões recentes - como a de Robert Formaini, que, pretendendo balanço sobre os empresários na teoria econômica, diz: 
“Karl Marx (1818-1883) ignored entrepreneurs altogether be cause they didn't fit in well with his division of the economic reality into the bourgeoisie and the proletariat, the 'capitalists' and the 'workers'. This seems an especially large oversight for the man who, according to Blaug (1997), introduced the concept 'technological change' into economic theory; because entrepreneurs are almost always linked with technical change, and Marx had the benefit of seeing many such entrepreneurial fortunes built on innovative ideas" (Formaini, 2001, p. 4).

Ao contrário do que argumenta Formaini, Marx não só não ignora a figura do empresário, como não há qualquer dificuldade em sua teoria de contemplar a ação empresarial, na medida mesmo em que se reconheça que a teoria da acumulação do capital só se realizará, inteiramente, quando se considerar o universo das diferenças trazidas pela disputa entre os vários capitais, os quais são mobilizados pelos empresários, que são seus sujeitos de vontade.

De resto, lembre-se que a valorização social, que a recepção da figura do empresário é sempre uma construção social, que depende, em larga medida, do momento conjuntural. Se em épocas de crescimento é freqüente a mitificação do empresário - o caso mais conspícuo, neste sentido, talvez seja o de Henri Ford e sua associação com os aspectos exitosos da dinâmica expansiva no sentido da geração da renda e emprego e melhoria das condições de vida dos trabalhadores - em momentos de crise, de desemprego e de concentração da renda, a figura do empresário é deslustrada, e isto tanto do ponto de vista da percepção comum, como mesmo perde centralidade na teoria econômica como o comprovam: as teses da tradição neoclássica austríaca e sua ênfase na figura do rentista; as teses da revolução dos gerentes - de Burnham a Galbraith; a tese de Schumpeter sobre o fim da destruição criadora, como o fim da ação inovativa do empresário, sufocado pela muralha burocrática da grande corporação; e, mais recentemente, a tese de Giovanni Arrighi (1996) sobre a existência de um momento "especulativo" nas fases finais dos ciclos sistêmicos de acumulação, quando o empresário, à moda de Schumpeter, é substituído pelo capitalista financeiro, agente do capital fictício.

\section{ORIGENS DA FIGURA DO EMPRESÁRIO NA TEORIA ECONÔMICA}

Se procurarmos pelo papel do empresário nas teorias econômicas convencionais, o que chamará nossa atenção é exatamente a relativa ausência desse personagem, que permaneceu por muito tempo negligenciado (Casson, 1990, p. 13). Se ele é figura que ocupa lugar destacado nos debates sobre política econômica ou desenvolvimento, sua função nos modelos e teorias microeconômicas é, quando muito, secundária. 
Não deixa de ser curioso que a razão desse descaso com a figura do empresário possa ser encontrada nas próprias características da teoria neoclássica da firma (Baumol, 1968; Casson, 1986). Nela, a empresa deve decidir sobre quantidades e preços de insumos e produtos, de modo a maximizar seu retorno, tomando por base um conjunto conhecido de funções de produção que relacionam de modo determinado os insumos e produtos. O que a firma faz é executar uma série de cálculos, reagindo às mudanças externas do ambiente econômico, de modo a assegurar-se de que continuará maximizando seu resultado. A conseqüência desse estilo de análise é clara:

"Obviously, the entrepreneur has been read out of the model. There is no room for enterprise or initiative. (...) One hears of no clever ruses, ingenious schemes, brilliant innovations, of no charisma or any of the other stuff of which outstanding entrepreneurship is made; one does not hear of them because there is no way in which they can fit into the model." (Baumol, 1968, p. 67)

Isso não quer dizer que não haja vestígios da figura do empresário na história do pensamento econômico. Ele certamente pode ser encontrado na obra dos clássicos do século XVIII e XIX, como Cantillon, Say e Marshall. Mais recentemente, ele comparece sobretudo, mas não de modo exclusivo, nos textos de autores que se colocaram à margem do mainstream - Schumpeter, Veblen, os economistas da escola austríaca. Ora, basta pensar nas diferenças entre estes autores para perceber que, a exemplo das artes ou da literatura, não é possível tratar de modo linear ou unívoco o sentido que a figura do empresário ocupa na análise econômica. Citando Baumol, mais uma vez,

"the entrepreneur is at the same time one of the most intriguing and one of the most elusive characters in the cast that constitutes the subject of economic analysis. (...) In the writings of the classical economists his appearance was frequent, though he remained a shadowy entity without clearly defined form and function. Only Schumpeter and, to some degree, Professor Knight succeeded in infusing him with life and in assigning to him a specific area of activity to any extent commensurate with his acknowledged importance.” (Baumol, 1968, p. 64)

Com efeito, Schumpeter e Knight são os representantes por excelência das duas principais vertentes analíticas que abordaram o problema. Se a primeira define o empresário como aquele indivíduo cuja função é inovar, para a outra ele é aquele que toma decisões em situações que envolvem incerteza.

A essência da posição de Schumpeter já estava definida desde 1911, na Teoria do desenvolvimento econômico: “chamamos 'empreendimento' à realização de combinações novas; chamamos 'empresários' aos indivíduos cuja função é reali- 
zálas" (Schumpeter, 1982, p. 54). Apesar das mudanças de ênfase ao longo de sua obra, que deixarão em segundo plano uma leitura romântica e individualista do empresário para acentuar a natureza planejada das inovações no interior das grandes corporações, sua posição básica não se alteraria: “...the entrepreneur and his function are not difficult to conceptualize: the defining characteristic is simply the doing of new things or the doing of things that are already being done in a new way (innovation)" (Schumpeter, 1947, p. 151). Definido dessa maneira, o papel do empresário não se confunde com o do administrador, pois, enquanto o primeiro empreende um negócio que incorpora uma nova idéia, o administrador se limita a gerir uma atividade já em curso. Também não se confunde com o do inventor, que é alguém que produz idéias, enquanto o empresário faz com que as coisas aconteçam (gets things done), pouco importando se isso envolve ou não algum conhecimento científico novo. Daí a já conhecida distinção entre invenção e inovação. Mas, é sobretudo a diferença traçada por Schumpeter entre o empresário e o capitalista (o proprietário dos meios de produção) que nos interessa aqui. Pois, a atividade inovadora envolve sempre o lidar com situações desconhecidas, incertas; aquilo que para todo indivíduo envolvido no fluxo circular é um dado familiar, rotineiro, torna-se para o inovador uma incógnita. Mas, para Schumpeter, o empresário não é aquele que corre riscos: "o risco obviamente recai sobre o proprietário dos meios de produção ou do capitaldinheiro que foi pago por eles, portanto nunca sobre o empresário enquanto tal. (...) O empresário nunca é aquele que corre o risco" (Schumpeter, 1982, pp. 54; 92). ${ }^{1}$

Nesse ponto, a abordagem schumpeteriana se separa da outra vertente analítica, que concebe a função empresarial exatamente como a de quem carrega o risco (risk bearing). Essa vertente ganha refinamento na obra de Frank Knight, com sua clássica distinção entre o risco - mensurável — e a incerteza. Para ele, numa situação ideal onde não houvesse incerteza, os homens poderiam se concentrar em fazer as coisas de um modo automático, dispondo de toda informação necessária para se adequarem às mudanças de ambiente de uma maneira mecânica. Mas se a incerteza entra em cena, o mero "fazer coisas", a execução de tarefas, torna-se uma atividade secundária e o que importa é decidir o "que" e o "como" fazer. Nesse caso, o reconhecimento da incerteza provocaria duas mudanças na organização da sociedade:

"In the first place, goods are produced for a market, on the basis of an entirely impersonal prediction of wants, not for the satisfaction of the wants of the producers themselves. The producer takes the responsibility of forecasting the consumers' wants. In the second place, the work of the forecasting and at the same time a large part of the technological

\footnotetext{
${ }^{1}$ E não se trata de frase isolada ou tomada fora de contexto. Sobre esse ponto, cf.: Schumpeter (1994, p. 556). Ver também Kanbur (1980).
} 
direction and control of production are still further concentrated upon a very narrow class of the producers, and we meet with a new economic functionary, the entrepreneur." (Knight, 1921, p. 268)

Em sua origem, esta abordagem remonta ao século XVIII. É exatamente com esse sentido que o termo empresário (entrepreneur) aparece pela primeira vez em um texto de teoria econômica: o Ensaio sobre a natureza do comércio em geral, de Cantillon. ${ }^{2}$ Ao discutir a composição dos habitantes de um Estado, Cantillon divide os indivíduos entre independentes (os proprietários de terras e o príncipe) e dependentes (todos os demais, porque subsistem do produto da terra, que é propriedade dos primeiros). Por sua vez, ele distingue duas classes entre os indivíduos dependentes: os empresários e os assalariados. O que caracteriza os assalariados é que eles dispõem de um rendimento certo ao longo do tempo, pouco importando se esse rendimento é um salário, pensão ou soldo. Todos os demais, quer tenham ou não um capital próprio, quer se tratem de fazendeiros, comerciantes, artesãos ou prestadores de serviços são empresários, porque vivem de modo incerto. ${ }^{3}$ Eles carregam o risco de comprar a um preço conhecido e vender a um preço incerto:

“...ils en donnent un prix certain suivant celui du lieu où ils les achètent, pour les revendre en gros ou en détail à un prix incertain. (...) Ces entrepreneurs ne peuvent jamais savoir la quantité de la consommation dans leur ville, ni même combien de temps leurs chalands achèteront d'eux, vu que leurs rivaux tâcheront par toutes sortes de voies de s'en attirer les pratiques: tout cela cause tant d'incertitude parmi tout ces entrepreneurs, qu'on en voit qui font journellement banqueroute." (Cantillon, 1952, pp. 29-30)

Depois de Cantillon, Say teria sido o primeiro a reconhecer a função econômica do empresário. ${ }^{4}$ No seu Tratado de Economia Política, o empresário é representado como aquele que, aproveitando-se dos conhecimentos postos à sua disposição pelos cientistas, reúne e combina os diferentes meios de produção para criar produtos úteis. Por outro lado — ainda segundo a visão estabelecida —, os autores ingle-

\footnotetext{
${ }^{2}$ O Ensaio foi escrito provavelmente por volta de 1730, mas só foi publicado em 1755. A prioridade de Cantillon no emprego do conceito é reconhecida por Casson (1986, p. 151) e Schumpeter (1994, p. 555), mas é claro que a palavra apareceu muito antes de ganhar seu sentido econômico.

${ }^{3}$ Analogamente, Knight (1921, p. 271) divide toda a renda da sociedade em dois tipos: renda contratual ou aluguel (rent) e renda residual ou lucro.

${ }^{4}$ Ao menos, é essa a opinião de boa parte dos historiadores. Schumpeter (1994, p. 555), por exemplo, afirma que "J. B. Say, moving along in the French (Cantillon) tradition, was the first to assign to the entrepreneur - per se and as distinct from the capitalist - a definite position in the schema of the economic process". Ver também Dobb (1934).
} 
ses e, em particular, Adam Smith, teriam falhado ao não distinguir a figura do empresário, identificando seu papel ao do capitalista. ${ }^{5}$

Nos últimos anos, esta opinião - que encontra-se expressa nos trabalhos de Blaug (1985, pp. 459-61) e Schumpeter (1994, pp. 222, 556) — foi objeto de severa e bem fundada crítica (Pesciarelli, 1989). ${ }^{6}$ Ao contrário do que se afirma, o conceito de empresário aparece na Riqueza das nações sob três diferentes formas. Em primeiro lugar, como adventurer, termo que poderia ser traduzido por aventureiro ou especulador, isto é, indivíduo que especula seu capital em empreendimentos difíceis e arriscados. Outra forma de empresário é o projector, termo que guardava uma clara ambigüidade, podendo significar tanto aquele que faz maquinações para trapacear ou roubar, quanto aquele que realiza planos ou executa uma "invenção honesta". De maneira geral, Smith é hostil tanto em relação ao adventurer quanto ao projector, condenando-os por levarem à falência as pessoas que se engajam em seus projetos insensatos, ou por queimarem os fundos destinados à manutenção dos trabalhadores. No entanto, há ainda uma terceira forma de empresário, o undertaker, para o qual Smith reserva sua simpatia. Também ele se dedica a realizar projetos, mas ao contrário do projector, age sempre com prudência e moderação. O homem prudente

“...does not go in quest of new enterprises and adventures, which might endanger, but could not well increase, the secure tranquillity which he actually enjoys. If he enters into any new projects or enterprises, they are likely to be well concerted and well prepared." (Smith, 1982, p. 215)

O que está em jogo aqui é o valor que Smith, o filósofo moral, atribui à virtude estóica da prudência, que o impede de aprovar as ações daqueles que especulam com idéias e projetos arriscados.

Por sua vez, essa posição irá lhe render a crítica de Bentham, para quem o projector é aquele que, ao introduzir inovações, promove o desenvolvimento da sociedade:

"[o termo projectors] falls (...) upon all such persons, as, in the pursuit of wealth, or even of any other object, endeavour, by the assistance of wealth, to strike into any channel of invention. (...) upon all such persons as, in the line of any of their pursuits, aim at any thing that can be called improvement; whether it consists in the production of any new article adapted to man's use, or in the meliorating the quality, or

\footnotetext{
${ }^{5}$ Essa visão remonta ao próprio Say (1983, p. 85): “os ingleses não tem uma palavra equivalente a empresário industrial. É isso, talvez, que os impediu de distinguir, nas operações industriais, entre, de um lado, o serviço que presta o capital e, de outro, o serviço que presta, por sua capacidade e talento, aquele que emprega o capital”.

${ }^{6}$ Além do artigo de Pesciarelli, em quem nos apoiamos extensamente, ver Muller (1995, p. 177-80).
} 
diminishing the expense, of any of those which are already known to us." (Bentham, 1987, p. 390)

Pesciarelli (1989) chama ainda atenção para o fato de que, dos cinco tipos de inovação citados por Schumpeter na Teoria do desenvolvimento econômico, ao menos quatro são mencionados por Bentham: a abertura de novos mercados, a descoberta de novas fontes de suprimentos, a produção de um novo bem e a introdução de um novo método de produção. Nesse sentido, não há qualquer exagero em apontar na obra de Bentham o ponto de partida daquela vertente schumpeteriana de compreensão do papel do empresário. ${ }^{7}$

\section{MARX, OS CAPITALISTAS E A LÓGICA DA ACUMULAÇÃO}

Na obra de Marx, o papel e o lugar do capitalista são os do capital. Ele não é senão a encarnação de uma potência alienada e alienante, o capital, que em sua dinâmica tanto coisifica relações sociais quanto personifica coisas.

Para Marx a realidade capitalista como que oblitera a subjetividade de seus sujeitos: não há lugar para vontades, desejos, sonhos, ações dos capitalistas que não estejam submetidos à lógica da acumulação. Diz Marx — "O capitalista só possui um valor perante a história e o direito histórico à existência enquanto funciona personificando o capital” (Marx, 1968, p. 688). Esta idéia será retomada várias vezes ao longo dos três livros de $\mathrm{O}$ capital. A função do capitalista é supervisionar o processo de produção, dirigi-lo, resultando disto certas contradições. Em O capital, livro I, Marx cita trechos de alguns de seus trabalhos anteriores em que o caráter contraditório da ação capitalista se manifesta: da Miséria da filosofia, ele resgata a idéia do caráter destrutivo/construtivo da burguesia (Marx, 1968, p. 749); do Manifesto comunista, lembra o trecho em que a burguesia aparece como portadora inconsciente do progresso industrial (Marx, 1968, p. 882). Também do Manifesto comunista é a idéia de que a burguesia não pode existir sem revolucionar continuamente o instrumental da produção (Marx, 1968, p. 557-558). Nos Grundrisse aparece a idéia de que o capital coloca todas as ciências a seu serviço e que transforma a invenção num ramo de negócios (Marx, 1972, p. 201).

Por outro lado, houve quem acusasse Marx de desconsiderar a especificidade do empresário, a exemplo do que, supostamente, teriam feito Smith e os economistas clássicos ingleses:

"And exactly the same thing is true of Marx. Despite his emphasis on the constant accumulation of capital, on the remorseless pressure to

\footnotetext{
7 O curioso é o fato de Schumpeter não se referir a Bentham quando discute a função do empresário, seja na Teoria do desenvolvimento econômico; seja na História da análise econômica.
} 
innovate or perish, Marx too treated the business process as virtually automatic once the required capital is forthcoming.” (Blaug, 1985, p. 461)

Este tipo de crítica, entretanto, não resiste ao confronto com os textos. Tomese, por exemplo, o capítulo 23 do livro III d'O capital. Ali, Marx se detém no de desenvolvimento do conceito de ganho (ou lucro) empresarial (Unternehmergewinn) que é o rendimento que cabe ao capitalista produtivo e que corresponde à diferença entre o lucro bruto e os juros pagos ao prestamista. Ainda que se possa tomar esta parcela como mera diferença quantitativa, o resultado do fato de o capitalista ter de recorrer a um empréstimo para compor seu capital, Marx não hesita em afirmar que ela se transforma em uma diferença qualitativa, na medida em se considera que todo capital (emprestado ou não) confere o direito a um juro. Vale aqui transcrever parte desta passagem:

"O capitalista funcionante é pressuposto aqui como não-proprietário do capital. A propriedade do capital é representada perante ele pelo prestamista, o capitalista monetário. $\mathrm{O}$ juro que paga a este aparece, portanto, como aquela parte do lucro bruto que cabe à propriedade do capital como tal. Em contraste com isso, a parte do lucro que cabe ao capitalista ativo aparece agora como ganho empresarial oriundo exclusivamente das operações ou funções que ele efetua com o capital no processo de reprodução, especialmente, pois, das funções que como empresário ele exerce na indústria ou no comércio." (Marx, 1984, p. 280; grifo nosso)

Apesar de Marx se referir explicitamente às funções que correspondem ao ganho empresarial, Blaug não hesita em afirmar que ele não se refere a nenhuma função econômica que corresponda àquela parcela do lucro, “... for example, the function of buying inputs at certain prices and selling output at uncertain prices, as a result of which there may be losses instead of profits" (1985, p. 461). Ao contrário do que se pretende, ao se referir às funções que o capitalista ativo desempenha no processo de reprodução do capital (em oposição à inatividade do capitalista monetário, o proprietário do capital), Marx não apenas diferencia o ganho empresarial do salário de superintendência ou administração, fazendo ver que o primeiro decorre do processo de exploração do trabalho, ${ }^{9}$ como afirma que a grandeza da primeira parcela depende de um conjunto variado de fatores que podem alterar as

\footnotetext{
${ }^{8}$ Schumpeter (1994, p. 556) argumenta, de maneira semelhante, que "for them - as well as for Marx - the business process runs substantially by itself, the one thing needful to make it run being an adequate supply of capital".

9 “Com o desenvolvimento da cooperação, por parte dos trabalhadores, das empresas por ações, por parte da burguesia, até o último pretexto para confundir o ganho empresarial com o salário de administração perdeu sua base e o lucro apareceu também na prática como o que era inegavelmente na teoria, como mera mais-valia (...); de modo que o capitalista funcionante realmente explora o trabalho,
} 
taxas de lucro, entre os quais "a maior ou menor astúcia e diligência do capitalista" ao comprar ou vender acima ou abaixo do preço de produção, o emprego de métodos produtivos acima da média e a economia de capital constante, inclusive pelo emprego de novas invenções (Marx, 1984, p. 279). ${ }^{10}$

Em uma pequena seção sobre as economias por meio de invenções, no livro III de O capital, Marx chama atenção para o fato de que "só a experiência do trabalhador combinado descobre e mostra onde e como economizar, como efetivar de modo mais simples as descobertas já feitas, quais os obstáculos que precisam ser superados na efetivação da teoria — sua aplicação no processo de produção etc." (Marx, 1984, p. 80). Enfatiza ainda o fato de que os empresários pioneiros, os introdutores de inovações, freqüentemente enfrentavam dificuldades, terminando por falir, pois operavam estabelecimentos industriais com "custos muito maiores" do que os dos estabelecimentos posteriores, erguidos sobre as ruínas dos primeiros. Neste sentido, conclui que, geralmente, "é a espécie menos valiosa e mais miserável de capitalistas argentários que tira o maior lucro de todos os novos desenvolvimentos do trabalho geral do espírito humano e de sua aplicação social pelo trabalho combinado" (Marx, 1984, p. 80).

$\mathrm{Na}$ visão de Marx é, portanto, clara a tese de que o capitalismo é a vitória dos Irmãos Cointet sobre David Séchard, a invenção, a poesia, a criatividade, a ciência, o gênio submetidos à uma potência coercitiva e irracional, que compele a humanidade a produzir por produzir, num processo destituído de sentido e marcado por dinâmica que gera, ao mesmo tempo e pelas mesmas determinações, abundância e escassez, miséria e riqueza, violência e embrutecimento.

\section{DE MARSHALL A VEBLEN: O AUGE E A DECADÊNCIA DO HERÓI}

A questão do papel do empresário, a busca de sua valorização e reconhecimento social são temas importantes do pensamento econômico do final do século XIX e início do XX. Autores como Marshall, Sombart, Veblen, Schumpeter e mesmo Keynes farão do empresário sujeito decisivo da vida econômica moderna. Na verdade, é possível dizer que toda esta geração de pensadores da economia será marcada por uma tensão no referente ao entendimento do papel do empresário, tensão que talvez possa ser posta assim: herói ou parasita?

e o fruto de sua exploração, quando trabalha com capital emprestado, divide-se em juros e ganho empresarial, excedente do lucro sobre o juro.” (Marx, 1984, p. 290).

\footnotetext{
${ }^{10}$ Noutra parte, ele acrescenta que "a diversidade das taxas de lucro e, portanto, dos próprios lucros, com igual exploração do trabalho, pode provir ainda de outras causas, mas pode decorrer também única e exclusivamente da diferença na habilidade empresarial com que se dirigem os dois negócios”. E acrescenta que "essa circunstância leva o capitalista a acreditar — convence-o — que seu lucro é devido não à exploração do trabalho, mas pelo menos parcialmente a outras condições, independentes dela, a saber, à sua ação individual.” (Marx, 1984, p. 106).
} 
Marshall vai ver no empresário o organizador da produção, o que corre riscos e por isto merecedor do lucro; quanto ao capitalista, o proprietário do capital-dinheiro, ao emprestá-lo padeceria de abstinência a qual seria recompensada com o recebimento de juros. Se há neutralidade funcional na perspectiva de Marshall, Keynes terá visão crítica do papel do capitalista, o qual, chamado de rentista, Keynes vê como merecedor de eutanásia tão "piedosa" quando necessária para o crescimento da renda e do emprego.

Schumpeter retomará o tema à sua maneira, definindo o empresário como aquele que realiza inovações tecnológicas, dando a este conceito uma ampla gama de sentidos. Na visão de Schumpeter, nem todo proprietário de empresa é empresário, reservando este nome para o herói da civilização burguesa, aquele que viabiliza a introdução de inovações.

Contudo, é com Sombart e Veblen que o tema do papel do empresário adquire centralidade no pensamento econômico. Sombart, em seu livro O apogeu do capitalismo, publicado em 1927, vê o empresário, o burguês como a primeira e decisiva força motriz do capitalismo. Em seu livro O burguês, de 1913, o tema é desenvolvido mais amplamente. Nesse livro, Sombart busca fixar o espírito capitalista identificando-o como uma síntese entre o espírito de empresa e o espírito burguês. Sendo que o espírito de empresa seria caracterizado pela paixão pelo dinheiro, pelo amor à aventura e pelo espírito de invenção; enquanto o espírito burguês seria marcado pela prudência reflexiva, pela circunspecção calculadora, pela ponderação razoável e pelo espírito de ordem e de economia (Sombart, 1953, p. 23).

Sombart, no Apogeu do capitalismo, vai identificar a existência de três tipos de empresários, correspondendo a três momentos da história do capitalismo: o técnico, hegemônico no início do capitalismo do século XV ao XVIII, o "capitão de indústria"; o comerciante, que surge na época de auge do capitalismo (1750-1914); e o financista, que é o tipo-ideal da época de auge do capitalismo (Sombart, 1984, p. 32-33).

Se há um inequívoco sentido positivo e progressivo na maneira como Sombart vê o empresário, a visão de Veblen sobre este mesmo tema será marcada pelo reconhecimento da existência de tensões e contradições no mundo do empresário. A obra de Veblen, o mais interessante dos economistas institucionalistas, é uma síntese original e compreensiva da vida econômica contemporânea, baseada na idéia de que a história humana é a história da evolução de instituições sociais, que têm como fundamento determinações que vão além da racionalidade instrumental. Neste sentido, a teoria de Veblen mobiliza categorias analíticas decorrentes da psicologia, da economia e da sociologia. O núcleo básico deste universo teórico é a tensão, a dicotomia constitutiva do ser humano entre instinto predatório e instinto construtivo. Em torno deste conflito básico, Veblen vai desenvolver em seus dois livros fundamentais - em 1899, a Teoria da classe ociosa; em 1904, a Teoria da empresa industrial — duas matrizes do comportamento econômico: o negócio e a indústria. Na matriz negócio estão os motivos: aquisição, lucro, dinheiro, o pro- 
prietário absenteísta, a propriedade privada; na matriz indústria estão as motivações: construção, produção e propriedade coletiva, cooperação. A primeira matriz, negócio, é a reposição do instinto predatório, isto é, da agressividade, da dominação, do conflito. A segunda matriz, indústria, diz respeito à curiosidade desinteressada, à criatividade afetiva, à perspectiva coletiva, grupal. A matriz negócio é o reino da classe ociosa, de ócio conspícuo, do consumo conspícuo, da emulação pecuniária, da exploração social, da exploração sexual. A matriz indústria é o locus do engenheiro, do técnico, do trabalhador.

Esta divisão, que marcaria o comportamento empresarial, tem para Veblen um sentido francamente decadentista. Para ele a hegemonia do motivo negócio em relação ao motivo indústria, que ele via acontecer em sua época, prenunciava a recessão crônica no campo econômico e a decadência moral permanente no campo sóciocultural. Sua morte, que coincide com a grande crise dos anos 1930 - e há aí um simbolismo importante - é a manifestação do desencontro do pensamento burguês com relação a seus sujeitos e objetos. Depois de Veblen, será difícil continuar a ver o burguês, o mundo dos negócios com as cores do heroísmo e da universalidade.

\section{SCHUMPETER, PENROSE E CHANDLER: FUNÇÕES EMPRESARIAIS E A EMERGÊNCIA DA EMPRESA INDUSTRIAL MODERNA}

Desde as últimas décadas do século XIX, três revoluções tecnológicas ocorreram (Freeman e Soete, 1997, pp. 66-70), e o poder das grandes corporações industriais cresceu. Se a teoria econômica já tinha problemas para lidar com a figura do empresário na era dos empreendimentos individuais, a emergência das grandes corporações tornou esse quadro mais complexo e difícil, levando ao surgimento de novas maneiras de tratar o tema.

Essa requalificação foi realizada de forma diferente por dois autores que têm em Schumpeter uma referência teórica importante: Penrose e Chandler. Se para Schumpeter coloca-se a obsolescência da função empresarial, para Penrose, a função empresarial é um dos serviços produtivos que alimentam o crescimento das firmas e, para Chandler, o empresário é o construtor da empresa industrial moderna. Essa diferenciação é interessante para localizar as novas dificuldades da teoria econômica para lidar com o tema do empresário nos tempos das grandes corporações.

Segundo Schumpeter (1984, p. 140-141), com o desenvolvimento do capitalismo o "estabelecimento ou a unidade de controle de grande escala" tornou-se a "máquina mais poderosa" do progresso econômico e "da expansão de longo prazo da produção total". Ele discute esse processo, avaliando os impactos da consolidação do papel das grandes firmas, entre os quais, a obsolescência da função empresarial. Esta função - que consiste em introduzir inovações e enfrentar resistências do ambiente econômico e social às coisas novas - estaria, segundo 
Schumpeter, perdendo terreno: em primeiro lugar, porque a "própria inovação está sendo reduzida a rotina" e, em segundo lugar, porque alguns "tipos de resistência - em particular, a resistência de consumidores e produtores a um novo tipo de coisa só porque é nova — já quase desapareceram” (1984: 174).

O progresso tecnológico, avalia Schumpeter,

"está se tornando assunto de equipes de especialistas treinados que criam o que lhes é pedido e fazem-no funcionar de maneira previsível. O romance da antiga aventura comercial rapidamente se desvanece, pois muitas das coisas que agora podem ser estritamente calculadas tinham, antigamente, de ser visualizadas num lampejo de gênio.” (1984, p. 174)

A ação individual tende a ser substituída por trabalho em equipe.

Estaria em operação um processo social que "solapa o papel e, junto com o papel, a posição social do empresário capitalista”. A burguesia depende do empresário. ${ }^{11} \mathrm{O}$ diagnóstico de Schumpeter sobre a sobrevivência do capitalismo deriva do sucesso da empresa capitalista: "a unidade industrial gigante perfeitamente burocratizada não apenas desaloja a pequena e média firma, mas ao final desaloja o empresário e expropria a burguesia como classe que, no processo, deve perder não apenas a sua renda mas também, o que é infinitamente mais importante, sua função" (1984, p. 176).

Penrose (1995) propõe uma teoria sobre o crescimento da firma. Em sua formulação define a firma tanto como uma organização administrativa como uma coleção de recursos produtivos. A firma é governada por suas "oportunidades produtivas", que compreende "all the productive possibilities that its 'entrepreneurs' see and can take advantage of". Penrose explicita que o termo entrepreneur é usado por ela num sentido funcional, referindo-se a indivíduos ou grupos que oferecem serviços empresariais (entrepreneurial services). Na definição de "serviços empresariais", retoma a interpretação schumpeteriana, na medida que esses serviços estão relacionados à introdução "in behalf of the firm" de novas idéias, à aquisição de novos recursos gerenciais, mudanças na organização administrativa da firma, no levantamento de recursos, etc. (Penrose, 1995, p. 31). Explicita ainda que serviços empresariais são contrastados com os serviços gerenciais.

Penrose discute as oportunidades para as pequenas firmas. Essas seriam construídas a partir dos prospective entrepreneurs que possuem apenas um pequeno capital e que estão necessariamente confinados em áreas onde "the only kind of requirements for getting some kind of start are a little capital and perhaps a training or a skill which is widespread among the non-professional working population"

\footnotetext{
11 Schumpeter explicita que "o grosso do que chamamos de industriais, comerciantes, financistas e banqueiros... estão no estágio intermediário entre a aventura empresarial e a mera administração corrente ou o domínio herdado" (p. 175).
} 
(1995, p. 221). O espaço para o crescimento das pequenas firmas são os interstícios da economia, áreas deixadas em aberto pelas grandes empresas (1995, p. 2223 ). As oportunidades para as pequenas firmas surgem também da difusão de conhecimentos tecnológicos: "...as technological knowledge grows and becomes increasingly diffused it will inevitably create innumerable and unpredictable opportunities for smaller firms" (1995, p. 224).

Ou seja, a formulação de Penrose rompe com o dilema de Schumpeter (grandes firmas minando a função empresarial), sugerindo que a competência nos serviços empresariais é crucial para o crescimento da firma ao afastar os limites gerenciais para o seu crescimento, ao mesmo tempo que aponta um espaço específico para as pequenas firmas e para os empresários que as constituem.

Por sua vez, Chandler $(1977,1990)$, apresenta uma interpretação das origens da “empresa industrial moderna”. Esta última é facilmente definida por duas características: ela contém muitas unidades operativas distintas (multidivisional) e é administrada por uma hierarquia de executivos assalariados (1977, p. 1). Com a chegada dessa nova instituição econômica, the managerial business enterprise, o mundo conheceu um novo tipo de capitalismo, "one in which the decisions about current operations, employment, output, and the allocation of resources for future operations were made by salaried managers who were not the owners of the enterprise" (1990, p. 2).

$\mathrm{Na}$ formulação de Chandler, minuciosamente desenvolvida em Visible Hand, a origem da empresa industrial moderna, um fenômeno norte-americano do final do século XIX, está relacionada com transformações revolucionárias nas condições de transporte e comunicação (ferrovias e telégrafos) e com as revoluções ocorridas na produção e na distribuição. Essas mudanças ofereceram oportunidades únicas para a exploração de economias de escala e de escopo.

Porém, três conjuntos de investimentos inter-relacionados foram essenciais para explorar essas oportunidades: 1) investimentos na produção, criando instalações produtivas suficientemente grandes para explorar as economias de escala e de escopo; 2) investimentos em marketing, criando redes de marketing e distribuição de forma a manter o volume de vendas à altura do volume de produção; 3 ) investimentos em gerência, contratando e treinando gerentes para administrar as instalações ampliadas e o pessoal na produção e distribuição, mas também para coordenar e monitorar essas duas funções básicas e planejar e alocar recursos para futura produção e distribuição. Apenas as firmas que realizaram estes três investimentos simultaneamente conseguiram explorar de forma vantajosa essas economias. As primeiras firmas a realizarem estes investimentos dominaram seus mercados.

Nesse contexto, Chandler situa a figura do empresário: os primeiros empresários a criar tais empresas adquiriram poderosas vantagens competitivas, "...their industries quickly became oligopolistic, that is, dominated by a small number of first movers" (1990, p. 8). Os empresários que realizaram os três investimentos ne- 
cessários para explorar as economias de escala e escopo criaram essa nova instituição que é a empresa industrial moderna. O pioneirismo é importante: as vantagens do first-mover são ressaltadas por Chandler (1990, p. 34-6). ${ }^{12}$

\section{CONCLUSÃO}

Schumpeter já afirmava que "any schema of the economic process must first of all settle the question of the dramatis personae to be admitted to the scene and thereby prejudge many of its features" (1994, p. 554). Ainda que a inclusão do empresário no rol dos personagens centrais do capitalismo contemporâneo pareça óbvia, a teoria econômica mainstream tem dificuldades consideráveis para definir o papel e as funções do empresário em seu esquema teórico, dificuldades que terminam por conduzir à sua virtual exclusão.

Por sua vez, o confronto com as obras de alguns dos clássicos do pensamento econômico demonstrou a existência de um conjunto diversificado — mas, nem sempre coerente - de tentativas de definir os atributos essenciais deste personagem. Obviamente, a simples mescla destas abordagens seria insuficiente para produzir uma formulação alternativa do conceito econômico do empresário: tal tentativa estaria fadado a simplificar os termos do problema e, nessa medida, falseá-lo.

Por outro lado, contrariando o temor de Schumpeter sobre a obsolescência da função empresarial, a complexificação da estrutura industrial, agora povoada por grandes corporações administradas profissionalmente, sugere que o papel deste personagem continua decisivo e pode estar ganhando novos contornos. Os autores abordados ao longo do nosso excurso oferecem elementos que deveriam ser retidos nos esforços analíticos para desenvolver um conceito de empresário adequado ao contexto econômico contemporâneo: a ênfase knightiana no elemento de incerteza que cerca as decisões empresariais sobre o "quê" e o "como" fazer as coisas; a distinção schumpeteriana — presente também em Marx — entre o empresário, o proprietário dos meios de produção e o mero administrador; a contribuição dos neoschumpeterianos que - sem descuidar do papel central das inovações na dinâmica capitalista - minimizam o elemento romântico no conceito de inovador, sugerindo que - a exemplo do que afirmavam Smith e Marx — as inovações são muitas vezes obra de um coletivo de trabalhadores, resultado da experiência do "trabalhador combinado"; e, finalmente, a insistência de Marx em apontar no empresário a personificação do capital processante — contraposto ao proprietário do capital - cuja função consiste em operar o processo de reprodução do capital e cujo ganho, nesta medida, decorre da exploração do trabalho.

\footnotetext{
12 Essa posição conquistada e mantida por first movers representa uma mudança estrutural frente a situação identificada por Marx (ver acima), onde o inovador falia e uma classe de money-capitalists dominava a indústria.
} 
Insista-se aqui, finalmente, que a teoria de Marx sobre a concorrência confere lugar importante à ação empresarial na dinâmica capitalista, tendo, nesse sentido, atualidade e pertinência insuspeitados se se considera o pensamento econômico dominante.

Resta apenas frisar que tais elementos, longe de resolverem o problema, são aqui sugeridos como pré-requisitos para que avanços na teoria da firma alimentem as investigações sobre o papel do empresário na realidade do capitalismo contemporâneo.

\section{REFERÊNCIAS BIBLIOGRÁFICAS}

ADORNO, Theodor W. e HORKHEIMER, Max. Dialética do Esclarecimento. Trad. port., Rio de Janeiro: Jorge Zahar, 1985.

ARRIGHI, Giovanni. O Longo Século XX. Trad. port., Rio de Janeiro: Contraponto, 1996. BAUMOL, W. Entrepreneurship in economic theory. American Economic Review, 58(2): 64-71, May 1968.

BENTHAM, J. Defence of usury (Letter XIII). In: MOSSNER, Ernest e ROSS, Ian (eds.). Correspondence of Adam Smith. Indianapolis: Liberty Fund, 1987.

BLAUG, M. Economic Theory in Retrospect. Cambridge: Cambridge U.P., 1985.

BUJÁRIN, Nicolai. La Economia Política del Rentista. Trad. esp., Buenos Aires: Pasado y Presente, 1974. CANTILLON, Richard. Essai sur la Nature du Commerce em Général. Paris : INED, 1952. CARLYLE, Thomas. Os Heróis. Trad. port., $2^{a}$ ed., São Paulo: Melhoramentos, 1963.

CASSON, M. Entrepreneur. In: EATWELL, John et alli (eds.). New Palgrave. New York: Macmillan, 1987.

. Introduction. In: CASSON, M. (ed.). Entrepreneurship. Aldershot: Edward Elgar, 1990. CHANDLER JR., A. The Visible Hand: the managerial revolution in America business. London: The Belknap Press of Harvard University Press, 1977.

. Scale and Scope: the dynamics of industrial capitalism. Harvard: Belknap, 1990.

. Organizational capabilities and the economic history of the industrial enterprise. Journal of Economic Perspectives, 6(3): 79-100, 1992.

COCHRAN, Thomas C. Actividad Empresarial. In: SILLS, David. Enciclopedia Internacional de las Ciencias Sociales. Trad. esp., vol. 4, Madrid: Aguilar, 1974.

DANBEZIES, A. Fausto. In: BRUNEL, P. (org.). Dicionário de Mitos Literários. $2^{\text {a }}$ ed., trad. port., Rio de Janeiro: José Olympio, 1998.

DOBB, M. Entrepreneur. In: SELIGMAN, E. (ed.). Encyclopaedia of the Social Sciences. New York: Macmillan, 1934.

FORMAINI, Robert L. The engine of capitalist process: entrepreneurs in economic theory, Economic and Financial Review, 4th quarter, 2001.

FREEMAN, C.; SOETE, L. The Economics of Industrial Innovation. London: Pinter, 1997.

KANBUR, S. M. A note on risk taking, entrepreneurship, and Schumpeter. History of Political Economy, 12(4): 489-98, Winter 1980.

KNIGHT, F. Risk, Uncertainty, and Profit. Boston: Houghton Mifflin, 1921.

LANDES, D. Prometeu desacorrentado. Trad. port., Rio de Janeiro: Nova Fronteira, 1994.

LEROY-BEAUliEU, Paul. Traité Théorique et Pratique D’Économie Politique, $2^{\circ}$ vol., $6^{\mathrm{a}}$ ed., Paris: Félix Alcan, 1914.

MARX, K. Los Fundamentos de la Crítica de la Economia a Política (Grundrisse...). Vol. 2, trad. esp., Madrid: Comunicación, 1972.

O Capital (Livro I). Trad. port., Rio de Janeiro: Civilização Brasileira, 1968.

. O Capital (Livro III, Tomo I). Trad. port., São Paulo: Abril Cultural, 1984. MULLER, J. 
Adam Smith in his time and ours. Princeton: Princeton U. P., 1995. NELSON, R. Capitalism as an engine of economic growth. Research Policy, 19(1), 1990.

PAVITT, K. Technologies, products and organization in the innovating firms: what Adam Smith tell us and Joseph Schumpeter doesn't. Industrial and Corporate Change, 7(3): 433-452, 1998.

PENROSE, E. The Theory of the Growth of the Firm. Oxford: Oxford University (third edition), 1995. PESCIARELLI, E. Smith, Bentham, and entrepreneurship. History of Political Economy, 21(3): 521-36, Fall 1989.

ROSDOLSKY, Roman. La significación de El Capital para la investigación marxista contemporánea. In: FAY, Victor (org.). Leyendo el Capital. Trad. esp., Madrid: Fundamentos, 1972. ROSENBERG, N. Why do firms do basic research (with their money)? Research Policy, 19: 165-174, 1990.

SAY, J.-B. Tratado de Economia Política. Trad. port., São Paulo: Abril Cultural, 1983. SCHUMPETER, J. Capitalismo, Socialismo e Democracia. Trad. port., Rio de Janeiro: Zahar Editores, 1984. . A Teoria do Desenvolvimento Econômico. Trad. port., São Paulo: Abril Cultural, 1982. . History of Economic Analysis. London: Routledge, 1994.

. The creative response in economic history. The Journal of Economic History, 7(2): 149-59, November 1947.

SMITH, A. The Theory of Moral Sentiments. Indianapolis: Liberty Fund, 1982. SOMBART, W. El Apogeo del Capitalismo. Vol. I, $2^{\text {a }}$ ed., trad. esp., México: FCE, 1984. . El Burgues. Trad. esp., Buenos Aires: Oresme, 1953.

SPENGLER, Oswald. La Decadencia de Occidente. Trad. esp., $1^{\circ}$ vol., Buenos Aires/México: ESPASACALPE, 1952.

TAWNEY, R. H. A Religião e o Surgimento do Capitalismo. Trad. port., São Paulo: Perspectiva, 1971. VEBLEN, Thorstein. A Teoria da Classe Ociosa. Trad. port., São Paulo: Pioneira, 1965. . A Teoria da Empresa Industrial. Trad. port., Porto Alegre: Globo, 1967. 